\section{Modelos de escritura y ornamentos en gráficas identificativas de edificios históricos de Tampico}

Rebeca Isadora Lozano Castro ${ }^{(1)}$ y Andrea Daniela Larrea Solórzano ${ }^{(2)}$

Resumen: La ciudad de Tampico en México es un puerto industrial y comercial marcado por su extracción de yacimientos petroleros a principios del siglo XX (1911-1938). Su historia fue descrita por extranjeros estadounidenses, ingleses y holandeses que pertenecieron a la industria petrolera, con estilos de vida alejados del local que se representaron en el estilo arquitectónico construido en casas y edificios multifamiliares. Estas estructuras forman parte de la historia materializada cultural y comunicacionalmente por medio de inscripciones, modelos de escritura (Gray, 1960) o símbolos gráficos en sus fachadas como identificación, que denominamos gráficas identificativas históricas.

Los objetos de diseño representan el color local histórico pluricultural de esa parte del mundo plagado de ornamentaciones conformas figurativas, como: hojas de acanto en la decoración de raíces nacionales, estilos gráficos auténticos, uso de proporciones en alto y bajo relieve, así como manejo de materiales de construcción de la época (concreto, ladrillo, granito, entre otros).

Esta investigación presenta algunos de los resultados obtenidos del estudio morfológico y simbólico de los elementos ornamentales presentes en esos objetos culturales de diseño, como reflejo de su devenir estilístico durante el s. XIX - s. XX. La interpretación de esas construcciones gráficas sugiere un orden, un equilibrio, una textura, un ritmo, una simetría, una coherencia formal de la composición histórica representada en su materialidad arquitectónica.

Palabras clave: Modelos de escritura - simbolismo representado - significación histórica.

[Resúmenes en inglés y portugués en la página 106]

(1) Docente Investigador Universidad Autónoma de Tamaulipas, Facultad de Arquitectura, Diseño y Urbanismo.

(2) Docente Investigador. 


\section{Introducción}

Las gráficas identificativas históricas como parte de los antecedentes del diseño gráfico corporativo y los modelos de escritura en la arquitectura de Tampico fueron resultado de acontecimientos políticos, económicos y socioculturales a partir de la Revolución Industrial y la época de auge petrolero en México. La dialéctica del diseño gráfico transitó en su materialidad y se fusionó con otros estilos de corrientes artísticas de las que resultaron hibridaciones, transformaciones y acumulaciones gráficas comunicacionales representadas en etapas: 1. porfiriana (1876-1910), 2. el movimiento revolucionario (1910-1917) y 3. el inicio de la industria petrolera en México (1911-1938). La presencia de inscripciones o modelos de escritura o símbolos gráficos con base a nombres, iniciales, símbolos, escudos, entre otros, han estado expuestos de forma escultural con materiales de construcción en el área principal de las fachadas arquitectónicas de edificaciones en el sector histórico de la ciudad y zonas aledañas. Sobre estos elementos la cultura material se plasmó gráficamente como unidad interrelacionada entre teoría y práctica cultural social, reflejo de estilos de vida, mitos y costumbres.

El presente análisis surge de un trabajo macro denominado "Memoria gráfica del diseño tampiqueño" (Lozano et al., 2020)en el cual se toman como muestra 104 gráficos identificativos, compuestos de características formales y visibles en cuanto a su modelo de escritura, color, forma, textura, movimiento, además se consideran sus dimensiones, la simetría, el énfasis, entre otros aspectos que permiten establecer una lectura visual.

En este recorrido analítico visual, por un lado, se observó la pluriculturalidad establecida por quienes habitaron el sector en la época determinada (inglesa, estadounidense, belga, holandesa, española, francesa, alemana, china, árabe, principalmente), cuyos rasgos culturales fueron representados en las corrientes artísticas adoptadas, como: Art Nouveau o Modernismo, Art Decó, Neoclásico o Neostilo, Funcionalismo, Eclecticismo, entre las más destacadas. Por otro, el simbolismo se dejó notar con rasgos característicos por medio de texturas, colores, y expresiones que permitieron la distinción cultural (origen, intención, economía y mediatización).

Por tanto, estas gráficas identificativas se han estudiado como objetos simbólicos, que conllevan una carga sensorial por lo cual su lectura varía según las referencias culturales que posee quien las observa; pues, no produce las mismas sensaciones hacia todos quienes se relacionan con estos signos, considerando que "las representaciones visuales cambian de función cuando cambian de contexto y cuando cambia la persona que las lee” (Larrea, 2020, p. 71).En este marco las gráficas identificativas y los ornamentos arquitectónicos presentes en el paisaje de Tampico se convierten en objetos signos $-\mathrm{y}$ al mismo tiempo en signos culturales- cuyos significados se mantienen en el tiempo. 


\section{Características formales de las gráficas identificativas: modelos de escritura y ornamentos}

Cuando se interpreta un objeto de diseño a partir de su lectura simbólica, es preciso reconocer sus elementos constitutivos (morfológicos, cromáticos, estructurales), la disposición de éstos (tamaños, texturas, movimientos, contrastes, luces, recursos tipográficos, entre otras cualidades) y el contexto cultural donde fueron creados. La interpretación de las representaciones visuales, sus componentes morfológicos y derivaciones de la estructura plástica posibilitan la comprensión de su significación.

Las formas orgánicas, por ejemplo, se valoraron en sus expresiones internas o cóncavas, externas o convexas, en función de su movimiento y su equilibrio, con orden, regularidad y tamaño o peso, tomando en cuenta las partes estructurales de los diseños.

Adicionalmente, se analizaron las formas rígidas y geométricas con referencia a su esqueleto constructivo con simetría dinámica, mismo que surge de un sistema de relaciones variadas, dando apariencia de ritmo visual con movimiento o equilibrio.

Además, en torno a la letra, como modelo de escritura en la arquitectura y los ornamentos, se consideraron: 1) La forma, por su exterior (convexo) y su interior (cóncavo) definiendo el volumen espacial y tamaño; 2) La posición en el espacio y su distribución horizontal, vertical o central, así como las relaciones entre los elementos y la superficie como realidad física inherente; 3 ) El alto y bajo relieve como indicador de textura (a través de variaciones del material y cualidades de otro sentido entorno al tacto); 4) El movimiento o ritmo en formas estáticas que proyecta a través de las formas la apariencia de una acción o dinamismo (Dondis, 1990); 5) La proporción comprendida como la relación en la magnitud, cantidad o grado de un elemento frente a otro (Gillam, 1980); 6) La simetría o asimetría, en referencia al equilibrio visual que predomina en las fachadas (Dondis, 1990); 7) Los ornamentos, que guardan significados específicos en cada caso, y que se describen en el siguiente punto; 8) En la letra se consideró el énfasis o intervención de acuerdo con al peso (más ancha o menos ancha) o potencia del mensaje usado con recursos como condensación, expansión, grosor, finura, inclinación.

Los efectos ornamentales en los modelos de escriturase lograron con el decorado de la letra en sus elementos constitutivos, extravagancia en terminaciones o vértices; ornamentos inspirados en peces, aves o incluso figuras humanas; orlas, viñetas, frisos y florones (Meyer, 2004).No obstante, es necesario señalar que el número de elementos simbólicos encontrados en las ornamentaciones fue ilimitado, empero, las formas previamente descriptas resumen y agrupan algunos elementos principales encontrados en las fachadas sujeto de estudio.

\section{Objetivos}

El objetivo general de esta investigación fue determinar desde un punto de vista descriptivo y cuantitativo, las características formales y patrones detallados de los objetos gráficos 
identificativos históricos que pertenecen al patrimonio edificado de la ciudad de Tampico con el propósito documentar y preservar la fisonomía iconográfica de la ciudad.

El objetivo general se concreta en tres objetivos particulares:

1. Registrar los objetos gráficos por tipo de inscripción, modelo de escritura o símbolo gráfico.

2. Clasificar los objetos gráficos con el propósito de establecer patrones visuales.

3. Interpretar formalmente la iconografía de los modelos de escritura y ornamentos.

\section{Metodología}

Esta investigación se fragmentó en tres momentos de trabajo y revisión. El primer término de trabajo se refirió a la observación y registro de los objetos con inscripciones, modelos de escritura o símbolos gráficos integrados a la arquitectura de edificios históricos de la ciudad de Tampico. Con los insumos obtenidos se dio lectura a formas específicas, interpretando desde analogías hasta convencionalismos; se registraron similitudes, contrastes y componentes a partir de una categorización en función del fenómeno visual específico que se desea destacar. Después se procedió con un despiece de los elementos que configuraron el objeto visual buscando los orígenes compositivos coligados a las formas y estructuras básicas, para la articulación de las partes en convenciones simples de cuya relación surge la forma total.

De ese modo, al realizar un análisis morfológico, primero, se examinó la estructura del objeto en el cual está la forma amoldada, después, se establecieron los componentes de la estructura plástica para determinación de la sintaxis formal presente en la pieza analizada. Ese proceso respondió a una permanente decodificación que permitió crear una nueva codificación, recreada por medio del análisis pluridisciplinar de las formas.

La interpretación partió de la observación de la proyección de forma y contraforma, pues poseen un carácter reversible y formulan perceptualmente dos imágenes alternadas. La forma poseyó mayor identidad visual, mientras que la contraforma fue indefinida, pero, en su conjunto permitieron comprender la globalidad formal. Estas formas se asociaron entre sí por relaciones plásticas tales como: coincidencia, distanciamiento, adyacencia, superposición, intersección, adición o sustracción, que configuran la sintaxis visual.

\section{Resultados}

Considerando a los signos ornamentales como componentes primarios del análisis iconográfico desplegado en este estudio, se realizó un recorrido crítico por la globalidad de las imágenes relevadas buscando reconocer los valores culturales y sociales contenidos en cada modelo arquitectónico. Las representaciones visuales analizadas, por sí solas, no revelaron un contenido simbólico; esta lectura fue posible dada la articulación en un len- 
guaje simbólico que es comprendido dentro de un contexto delimitado. De este modo, la significación expresada por las gráficas ornamentales de las fachadas de Tampico es comprensible al interior de su semiosfera cultural (Lotman, 1996), en la que coexisten núcleos simbólicos, que presentan un carácter delimitado dentro de un marco histórico-cultural, pero que se hibridan en el contacto constante con otras configuraciones similares.

El abordaje desplegado sobre la memoria gráfica de las fachadas de Tampico -a partir de un enfoque múltiple, sociocultural- da cuenta de las significaciones atribuidas históricamente por los primeros públicos, y por los públicos ulteriores que en la actualidad transitan en medio de este paisaje arquitectónico, de modo tal que esta reflexión abarca los cambios estilísticos que se evidencian a través de prácticas ornamentales. Así, el discernimiento sobre las formas materializadas a través de objetos gráficos comunicacionales y culturales dentro del tejido urbano, son una muestra del testimonio sígnico de etapas pasadas (s. XIX - s. XX).

Por este motivo, está investigación, situó cada uno de los elementos ornamentales en su contexto específico, para identificar a partir de cada una de sus piezas los significados generales, pues, en ocasiones estos signos son reconocibles como elementos únicos, "pero su velada existencia hace que se intensifique la búsqueda de su sentido, de su mensaje" (Frutiger, 2007, p. 47).

En cada una de las formas simbólicas abordadas se han rastreados sus orígenes constitutivos, por ejemplo, muchos elementos básicos fueron extraídos de la naturaleza,-como las flores, las conchas o las hojas de laurel-, sin embargo, su significación, para el pueblo de Tampico, está anclada más allá de su significación primaria.

\section{Conclusiones}

De acuerdo con los resultados obtenidos podemos afirmar que el registro, clasificación e interpretación de las gráficas identificativas histórica en fachadas de edificaciones de Tampico presentaron características y patrones detallados con estilizaciones de valores sociales, mitos y tradiciones, estatus. La moda representada se llevó como memoria de estilo ornamental, decorativo con raíz en lo nacional, neocolonial, y materiales característicos de la época.

El diálogo costumbrista y tradicional se expresó con formas y colores arquitectónicos históricos, curvas o trazos libres, nombres metafóricos, entre otros. Las texturas, materiales y lenguajes en la historia y el contexto, articulados y desplazados, formaron la identidad visual del paisaje urbano. La identidad originaria apareció como articulación de elementos representativos de identificación en esa realidad social.

Abstract: The city of Tampico in Mexico is an industrial and commercial port marked by its extraction from oil fields at the beginning of the 20th century (1911-1938). Its history 
was described by American, English and Dutch foreigners who belonged to the oil industry, with lifestyles away from the local that were represented in the architectural style built in houses and multi-family buildings. These structures are part of the culturally and communicationally materialized history through inscriptions, writing models (Gray, 1960) or graphic symbols on their facades as identification, which we call historical identification graphics.

The design objects represent the multicultural historical local color of that part of the world full of ornamentation with figurative forms, such as: acanthus leaves in the decoration of national roots, authentic graphic styles, use of proportions in high and low relief, as well as handling of construction materials of the time (concrete, brick, granite, among others).

This research presents some of the results obtained from the morphological and symbolic study of the ornamental elements present in these cultural design objects, as a reflection of their stylistic evolution during the s. XIX - s. XX. The interpretation of these graphic constructions suggests an order, a balance, a texture, a rhythm, a symmetry, a formal coherence of the historical composition represented in its architectural materiality.

Keywords: Writing models - represented symbolism - historical significance.

Resumo: A cidade de Tampico no México é um porto industrial e comercial marcado pela extração de campos de petróleo no início do século XX (1911-1938). Sua história foi narrada por estrangeiros americanos, ingleses e holandeses que pertenciam à indústria do petróleo, com estilos de vida distantes do local que eram representados no estilo arquitetônico construído em casas e edifícios multifamiliares. Essas estruturas fazem parte da história materializada cultural e comunicacionalmente por meio de inscrições, modelos de escrita (Gray, 1960) ou símbolos gráficos em suas fachadas como identificação, o que chamamos de gráficos de identificação histórica.

Os objetos de design representam a cor multicultural histórica local daquela parte do mundo repleta de ornamentação com formas figurativas, tais como: folhas de acanto na decoração de raízes nacionais, estilos gráficos autênticos, uso de proporções em alto e baixo relevo, bem como manuseio de materiais de construção da época (concreto, tijolo, granito, entre outros).

Esta pesquisa apresenta alguns dos resultados obtidos no estudo morfológico e simbólico dos elementos ornamentais presentes nestes objetos de design cultural, como reflexo da sua evolução estilística ao longo dos anos. XIX - s. XX. A interpretação dessas construções gráficas sugere uma ordem, um equilíbrio, uma textura, um ritmo, uma simetria, uma coerência formal da composição histórica representada em sua materialidade arquitetônica.

Palavras chave: Padrões de escrita - simbolismo representado - significado histórico.

[Las traducciones de los abstracts fueron supervisadas por el autor de cada artículo] 